\title{
Firearm-related injuries and deaths in Ontario, Canada, 2002-2016: a population-based study
}

\author{
David Gomez MD PhD, Natasha Saunders MD, Brittany Greene MD, Robin Santiago MSc, \\ Najma Ahmed MD PhD, Nancy N. Baxter MD PhD
}

- Cite as: CMAJ 2020 October 19;192:E1253-63. doi: 10.1503/cmaj.200722

\begin{abstract}
BACKGROUND: Firearm-related injury is an important and preventable cause of death and disability. We describe the burden, baseline characteristics and regional rates of firearm-related injury and death in Ontario.
\end{abstract}

METHODS: We conducted a populationbased cross-sectional study using linked data from health administrative data sets held at ICES. We identified residents of Ontario of all ages who were injured or died as a result of a firearm discharge between Apr. 1, 2002, and Dec. 31, 2016. We included injuries classified as assault, unintentional, self-harm or undetermined intent secondary to handguns, rifles, shot- guns and larger firearms. The primary outcome was the incidence of nonfatal and fatal injuries resulting in an emergency department visit, hospital admission or death. We also describe regional and temporal rates.

RESULTS: We identified 6483 firearmrelated injuries (annualized injury rate 3.54 per 100000 population), of which $2723(42.3 \%)$ were fatal. Assault accounted for $40.2 \%(1494 / 3715)$ of nonfatal injuries and 25.5\% (694/2723) of deaths. Young men, predominantly in urban neighbourhoods, within the lowest income quintile were overrepresented in this group. Injuries secondary to self-harm accounted for $68.0 \%$
(1366/2009) of injuries and occurred predominantly in older men living in rural Ontario across all income quintiles. The case fatality rate of injuries secondary to self-harm was $91.7 \%$. Self-harm accounted for 1842 deaths (67.6\%).

INTERPRETATION: We found that young urban men were most likely to be injured in firearm-related assaults and that more than two-thirds of selfharm-related injuries occurred in older rural-dwelling men, most of whom died from their injuries. This highlights a need for suicide-prevention strategies in rural areas targeted at men aged 45 or older.

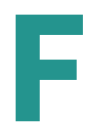

irearm injury is an important cause of death and disability. Canada's age-standardized firearm-related mortality rate ranks ninth highest among 36 peer Organisation for Economic Co-operation and Development countries. ${ }^{1}$ Between 2013 and 2017, 16 of Canada's Census metropolitan areas experienced an increased rate of firearm-related violent crime. ${ }^{2}$ During the same period, there was a $20 \%$ increase in the homicide rate in Canada, from 1.45 to 1.8 per 100000 population, with almost half $(43 \%)$ of the increase occurring in Toronto. ${ }^{3}$ One in 3 homicides in Canada in 2016 was firearm-related, and the proportion is increasing. ${ }^{3}$ Although homicide by firearm frequently receives prominent media attention, the majority (79\%) of firearm-related deaths in Canada are caused by suicide. ${ }^{4-6}$ Suicide is the second-leading cause of death in young people in Canada, and suicide by firearm carries the highest case fatality of all methods. ${ }^{7}$ Data from 2 decades ago showed that older men in rural areas were dis- proportionately affected by suicide by firearms and that there were no differences in suicide rates across the urban-rural continuum for women. ${ }^{8}$

Canadian statistics on firearm injuries have focused primarily on homicides and completed suicides. ${ }^{9-13}$ Excluding nonfatal injuries substantially underestimates the burden of disease secondary to firearm injuries. ${ }^{14}$ Nonfatal firearm injuries can lead to lasting morbidity, with major sequela that affect not only the victim but also the family. ${ }^{14-17}$ In addition, both fatal and nonfatal firearm-related injuries place a major burden on the health care system. ${ }^{16}$ However, nonfatal firearm-related injuries in Canada are largely unmeasured. Delineating the actual burden of firearm-related injury is essential to a coordinated public health response to this preventable cause of morbidity and mortality. Our primary objective was to describe the burden, baseline characteristics and regional rates of firearm-related injury and death in Ontario. 


\section{Methods}

\section{Setting, study design and data sources}

We conducted a population-based cross-sectional study using linked data from health administrative data sets held at ICES. ICES is an independent, nonprofit research institute whose legal status under Ontario's health information privacy law allows it to collect and analyze health care and demographic data, without consent, for health system evaluation and improvement. Data sets accessed included the Ontario Health Insurance Plan (OHIP) (a publicly funded health care system characterized by universal coverage for all medically necessary services), the Registered Persons Database (which captures demographic data for all Ontario residents who are eligible for care under the OHIP), the National Ambulatory Care Reporting System (which captures demographic, diagnostic, procedural and discharge data for all emergency department visits), the Canadian Institute for Health Information Discharge Abstract Database (which captures similar data for all acute care hospital admissions) and the Office of the Registrar General Deaths (which contains information on all deaths registered in Ontario, and captures cause and location of death). These data sets were linked by means of unique encoded identifiers and analyzed at ICES; linkage rates are $95 \%$ or greater.

\section{Study population}

We identified residents of Ontario of all ages with a valid OHIP number who were injured or died as a result of a firearm discharge between Apr. 1, 2002, and Dec. 31, 2016. We included injuries and deaths classified as assault, unintentional (i.e., accidental), self-harm and undetermined intent according to the World Health Organization international classification of external causes of injury secondary to handguns, rifles, shotguns and larger firearms using International Statistical Classification of Diseases and Related Health Problems, 10th Revision, enhanced Canadian version (ICD-10-CA) $\operatorname{codes}^{18}$ (Appendix 1, available at www.cmaj.ca/lookup/doi/10.1503/cmaj.200722/ tab-related-content). Injuries coded as being specifically secondary to airguns, paintball guns or spring-operated guns were excluded, as these are not considered firearms under the 1995 Canada Firearms Act. ${ }^{19}$ Injuries secondary to legal intervention were also excluded.

Gunshot wounds, regardless of severity, are considered mandatory reporting events, as defined by the College of Physicians and Surgeons of Ontario and the Mandatory Gunshot Wounds Reporting Act, 2005..$^{20}$ To capture people who died outside of hospital (who would not be identified in the National Ambulatory Care Reporting System or the Discharge Abstract Database), all those who had a cause of death consistent with a firearm injury as defined above were identified in the Office of the Registrar General Deaths database and were classified as dying outside of hospital.

\section{Outcome measures}

The primary outcome was the incidence of nonfatal and fatal injuries secondary to firearms resulting in an emergency depart- ment visit, hospital admission or death between Apr. 1, 2002, and Dec. 31, 2016. The main mortality measure was in-hospital or out-of-hospital death up to 30 days after the injury, determined from the Discharge Abstract Database/National Ambulatory Care Reporting System or the Office of the Registrar General Deaths.

\section{Covariates}

We considered demographic factors that may be associated with injury or death from firearms, including age, sex, socioeconomic status (neighbourhood income quintile at the dissemination area level using Canadian Census data), ${ }^{21}$ rurality (based on the Rurality Index for Ontario as large urban [0-9], small urban [10-40] or rural $\left.[\geq 40]^{22}\right)$ and geographic factors (Census division of residence). Rurality and neighbourhood socioeconomic status were based on the postal code of residence and not the location of injury.

\section{Statistical analysis}

We calculated age- and sex-standardized population-based rates of firearm-related injury and death per 100000 population. We calculated annualized and yearly rates with $95 \%$ confidence intervals over the 15-year study period. We calculated upper and lower confidence limits using the $\gamma$ distribution. We calculated firearmrelated injury rates as the sum of the total number of injuries and deaths as the numerator and population counts as the denominator. Finally, we calculated firearm-related death rates as the total number of firearm-related deaths per 100000 population. We used direct standardization, with the 2016 Canadian Census as the reference population. We also calculated rates by intent, age, sex, socioeconomic status and rurality. Age was summarized by 10 -year intervals in the tables to avoid small cell sizes. We categorized socioeconomic status based on the Census-based neighbourhood income quintile. We calculated the case fatality rate as the total number of deaths due to firearms divided by the total number of firearm-related injuries, stratified by intent.

We also describe regional rates of firearm-related injury stratified by intent based on rurality and Census divisions. Ontario has 49 Census divisions comprising municipalities, regional municipalities, counties and districts. We determined rurality and Census division based on the forward sortation area of the postal code of residence of the victim. We generated annualized rates of firearm-related injury and death for urban and rural areas, as well as for each Census division, stratified by intent. We assessed trends over time using the Cochran-Armitage test.

\section{Ethics approval}

The use of these data is authorized under section 45 of Ontario's Personal Health Information Protection Act, which does not require review by a research ethics board.

\section{Results}

During 2002-2016, there were 6483 firearm-related injuries in Ontario, for an overall age- and sex-adjusted firearm-related annualized injury rate of 3.58 per 100000 population (Table 1 ). More than half of injuries (3760 [58.0\%]) were nonfatal. The overall case fatality rate was $42 \%$, for an overall age- and sex- adjusted 
firearm-related annualized mortality rate of 1.49 per 100000 population. Most deaths (2287 [84.0\%]) occurred outside of hospital. One-third of injuries (2188 [33.7\%], 1.20 per 100000 ) were secondary to assault, and the remaining two-thirds (4295 [66.2\%], 2.34 per 100 000) were non-assault injuries (self-harm in 2009 cases, 1.10 per 100 000; unintentional in 1981 cases, 1.08 per 100 000; and undetermined in 301 cases, 0.16 per 100 000; in the remaining 4 cases intent was unknown) (Table 2 ).

One-third of injuries (2110 [32.5\%]) and 470 deaths (17.3\%) occurred in people aged 15-24 years, and almost one-third of injuries (2056 [31.7\%]) and just over half of deaths (1426 [52.4\%]) occurred in those aged 45 or older (Table 1$)$. The majority of injuries and deaths occurred in males, who had 12 times as many injuries and 15 times as many deaths as females. Disparities were also observed across income quintiles: people injured or killed were more likely to live in areas with the lowest neighbourhood income than in areas with the highest neighbourhood income. Overall case fatality was highest in the highest income quintile.

\section{Intent of injuries and deaths}

The rate of firearm-related injuries varied with age and intent (Figure 1). Assault was the most common intent among those aged 15-34, whereas self-harm was the most common intent among those aged 45 or more. Sociodemographic characteristics and outcomes were also different according to the intent of the firearm-related injury. Injuries secondary to assault were most common in young men living in predominantly urban neighbourhoods within the lowest income quintile. The case fatality rate of injuries secondary to assault was $31.7 \%$.

Table 1: Characteristics, rate per 100000 population and case fatality rate of firearm-related injuries and deaths

\begin{tabular}{|c|c|c|c|c|c|}
\hline Characteristic & $\begin{array}{c}\text { No. }(\%) \text { of } \\
\text { nonfatal and } \\
\text { fatal injuries } \\
n=6483\end{array}$ & $\begin{array}{c}\text { Rate per } \\
100000 \text { population } \\
(95 \% \mathrm{Cl})\end{array}$ & $\begin{array}{c}\text { No. }(\%) \text { of } \\
\text { deaths } \\
n=2723\end{array}$ & $\begin{array}{c}\text { Rate per } \\
100000 \text { population } \\
(95 \% \mathrm{Cl})\end{array}$ & $\begin{array}{c}\text { Case } \\
\text { fatality } \\
\text { rate, } \%\end{array}$ \\
\hline Overall & & 3.58 & & 1.49 & 42.0 \\
\hline \multicolumn{6}{|l|}{ Age group, yr } \\
\hline$<15$ & $129(2.0)$ & $0.41(0.34-0.48)$ & $21(0.8)$ & $0.07(0.04-0.10)$ & 16.3 \\
\hline $15-24$ & $2110(32.5)$ & $8.95(8.58-9.34)$ & $470(17.3)$ & $1.99(1.82-2.18)$ & 22.3 \\
\hline $25-34$ & $1288(19.9)$ & $5.33(5.05-5.63)$ & $409(15.0)$ & $1.69(1.53-1.87)$ & 31.7 \\
\hline $35-44$ & $900(13.9)$ & $3.27(3.06-3.49)$ & $397(14.6)$ & $1.44(1.30-1.59)$ & 44.1 \\
\hline $45-54$ & $790(12.2)$ & $2.84(2.65-3.05)$ & 465 (17.1) & $1.67(1.52-1.83)$ & 58.8 \\
\hline $55-64$ & $595(9.2)$ & $2.84(2.62-3.08)$ & $409(15.0)$ & $1.95(1.77-2.15)$ & 68.7 \\
\hline $65-74$ & $369(5.7)$ & $2.71(2.44-3.01)$ & $278(10.2)$ & $2.05(1.81-2.30)$ & 75.3 \\
\hline $75-84$ & $243(3.7)$ & $2.87(2.52-3.25)$ & $223(8.2)$ & $2.63(2.30-3.00)$ & 91.8 \\
\hline$>84$ & $59(0.9)$ & $1.90(1.45-2.45)$ & $51(1.9)$ & $1.64(1.22-2.16)$ & 86.4 \\
\hline \multicolumn{6}{|l|}{ Sex } \\
\hline Female & $523(8.1)$ & $0.57(0.52-0.62)$ & $176(6.5)$ & $0.19(0.16-0.22)$ & 33.6 \\
\hline Male & $5960(91.9)$ & $6.70(6.53-6.87)$ & $2547(93.5)$ & $2.86(2.75-2.98)$ & 42.7 \\
\hline \multicolumn{6}{|c|}{ Neighbourhood income quintile } \\
\hline 1 (lowest) & $2142(33.0)$ & $6.10(5.84-6.36)$ & $755(27.7)$ & $2.15(2.00-2.31)$ & 35.2 \\
\hline 2 & $1385(21.4)$ & $3.89(3.69-4.10)$ & $572(21.0)$ & $1.61(1.48-1.75)$ & 41.3 \\
\hline 3 & $1222(18.8)$ & $3.40(3.21-3.59)$ & $518(19.0)$ & $1.44(1.32-1.57)$ & 42.4 \\
\hline 4 & $909(14.0)$ & $2.44(2.28-2.60)$ & 430 (15.8) & $1.15(1.05-1.27)$ & 47.3 \\
\hline 5 (highest) & 729 (11.2) & $2.00(1.86-2.16)$ & $382(14.0)$ & $1.05(0.95-1.16)$ & 52.4 \\
\hline Unknown & $96(1.5)$ & - & $66(2.4)$ & - & 68.7 \\
\hline \multicolumn{6}{|l|}{ Rurality* } \\
\hline Large urban & $4342(67.0)$ & $3.33(3.23-3.43)$ & $1423(52.2)$ & $1.09(1.04-1.15)$ & 32.8 \\
\hline Small urban & $1180(18.2)$ & $3.35(3.16-3.55)$ & $682(25.0)$ & $1.94(1.79-2.09)$ & 57.8 \\
\hline Rural & 717 (11.0) & $5.20(4.83-5.59)$ & $468(17.2)$ & $3.39(3.09-3.72)$ & 65.3 \\
\hline Unknown & $244(3.8)$ & $15.24(13.38-17.27)$ & $150(5.5)$ & 9.37 (7.93-10.99) & 61.5 \\
\hline
\end{tabular}


Table 2: Characteristics and rate per 100000 population of firearm-related injuries stratified by intent*

\begin{tabular}{|c|c|c|c|c|c|c|c|c|}
\hline Characteristic & $\begin{array}{l}\text { Assault, } \\
\text { no. }(\%) \\
n=2188\end{array}$ & $\begin{array}{c}\text { Rate per } \\
100000 \\
\text { population } \\
(95 \% \mathrm{Cl})\end{array}$ & $\begin{array}{c}\text { Self-harm, } \\
\text { no. (\%) } \\
n=2009\end{array}$ & $\begin{array}{c}\text { Rate per } \\
100000 \\
\text { population } \\
(95 \% \mathrm{CI})\end{array}$ & $\begin{array}{c}\text { Unintentional, } \\
\text { no. }(\%) \\
n=1981\end{array}$ & $\begin{array}{c}\text { Rate per } \\
100000 \\
\text { population } \\
(95 \% \mathrm{CI})\end{array}$ & $\begin{array}{l}\text { Undetermined, } \\
\text { no. }(\%) \\
n=301\end{array}$ & $\begin{array}{c}\text { Rate per } \\
100000 \\
\text { population } \\
(95 \% \mathrm{Cl})\end{array}$ \\
\hline \multicolumn{9}{|l|}{ Age group, yr } \\
\hline$<15$ & $32(1.5)$ & $0.10(0.07-0.14)$ & $8(0.4)$ & $0.03(0.01-0.05)$ & $68(3.4)$ & $0.21(0.17-0.27)$ & $21(7.0)$ & $0.07(0.04-0.10)$ \\
\hline $15-24$ & $1016(46.4)$ & $4.31(4.05-4.59)$ & $160(8.0)$ & $0.68(0.58-0.79)$ & $823(41.5)$ & $3.49(3.26-3.74)$ & $111(36.9)$ & $0.47(0.39-0.57)$ \\
\hline $25-34$ & $610(27.9)$ & $2.53(2.33-2.73)$ & $170(8.5)$ & $0.70(0.60-0.82)$ & $464(23.4)$ & $1.92(1.75-2.10)$ & $43(14.3)$ & $0.18(0.13-0.24)$ \\
\hline $35-44$ & $275(12.6)$ & $1.00(0.88-1.13)$ & $305(15.2)$ & $1.11(0.99-1.24)$ & $277(14.0)$ & $1.01(0.89-1.13)$ & 41 (13.6) & $0.15(0.11-0.20)$ \\
\hline $45-54$ & $141(6.4)$ & $0.51(0.43-0.60)$ & $451(22.4)$ & $1.62(1.48-1.78)$ & $168(8.5)$ & $0.60(0.52-0.70)$ & $30(10.0)$ & $0.11(0.07-0.15)$ \\
\hline $55-64$ & $68(3.1)$ & $0.32(0.25-0.41)$ & $384(19.1)$ & $1.83(1.65-2.03)$ & $113(5.7)$ & $0.54(0.44-0.65)$ & $30(10.0)$ & $0.14(0.10-0.20)$ \\
\hline $65-74$ & $30(1.4)$ & $0.22(0.15-0.32)$ & $270(13.4)$ & $1.99(1.76-.24)$ & $53(2.7)$ & $0.39(0.29-0.51)$ & $15(5.0)$ & $0.11(0.06-0.18)$ \\
\hline $75-84$ & $10(0.4)$ & $0.12(0.06-0.22)$ & $213(10.6)$ & $2.51(2.19-2.88)$ & $13(0.6)$ & $0.15(0.08-0.26)$ & $7(2.3)$ & $0.08(0.03-0.17)$ \\
\hline$>84$ & $6(0.3)$ & $0.19(0.07-0.42)$ & $48(2.4)$ & $1.55(1.14-2.05)$ & $\leq 5$ & $0.06(0.01-0.23)$ & $\leq 5$ & $0.10(0.02-0.28)$ \\
\hline \multicolumn{9}{|l|}{ Sex } \\
\hline Female & $212(9.7)$ & $0.23(0.20-0.26)$ & $76(3.8)$ & $0.08(0.07-0.10)$ & $190(9.6)$ & $0.21(0.18-0.24)$ & $44(14.6)$ & $0.05(0.03-0.06)$ \\
\hline Male & $1976(90.3)$ & $2.22(2.13-2.32)$ & 1933 (96.2) & $2.17(2.08-2.27)$ & $1791(90.4)$ & $2.01(1.92-211)$ & $257(85.4)$ & $0.29(0.25-0.33)$ \\
\hline \multicolumn{9}{|c|}{$\begin{array}{l}\text { Neighbourhood } \\
\text { income quintile }\end{array}$} \\
\hline 1 (lowest) & $907(41.4)$ & $2.58(2.42-2.76)$ & $438(21.8)$ & $1.24(1.13-1.37)$ & $707(35.7)$ & $2.01(1.87-2.17)$ & $89(29.6)$ & $0.25(0.20-0.31)$ \\
\hline 2 & $501(22.9)$ & $1.41(1.29-1.54)$ & $422(21.0)$ & $1.19(1.08-1.31)$ & $400(20.2)$ & $1.12(1.02-1.24)$ & 60 (19.9) & $0.17(0.13-0.22)$ \\
\hline 3 & $355(16.2)$ & $0.99(0.89-1.10)$ & $421(21.0)$ & $1.17(1.06-1.29)$ & $388(19.6)$ & $1.08(0.97-1.19)$ & $58(19.3)$ & $0.16(0.12-0.21)$ \\
\hline 4 & $231(10.6)$ & $0.62(0.54-0.70)$ & $377(18.8)$ & $1.01(0.91-1.12)$ & $248(12.5)$ & $0.66(0.58-0.75)$ & $52(17.3)$ & $0.14(0.10-0.18)$ \\
\hline 5 (highest) & $152(6.9)$ & $0.42(0.35-0.49)$ & $322(16.0)$ & $0.89(0.79-0.99)$ & $218(11.0)$ & $0.60(0.52-0.68)$ & $37(12.3)$ & $0.10(0.07-0.14)$ \\
\hline \multicolumn{9}{|l|}{ Rurality $\ddagger$} \\
\hline Large urban & 1939 (88.6) & $1.49(1.42-1.55)$ & $815(40.6)$ & $0.62(0.58-0.67)$ & 1404 (70.9) & $1.08(1.02-1.13)$ & $184(61.1)$ & $0.14(0.12-0.16)$ \\
\hline Small urban & $130(5.9)$ & $0.37(0.31-0.44)$ & $640(31.8)$ & $1.82(1.68-1.96)$ & $345(17.4)$ & $0.98(0.88-1.09)$ & $61(20.3)$ & $0.17(0.13-0.22)$ \\
\hline Rural & $52(2.4)$ & $0.38(0.28-0.49)$ & $446(22.2)$ & $3.23(2.94-3.55)$ & $175(8.8)$ & $1.27(1.09-1.47)$ & $44(14.6)$ & $0.32(0.23-0.43)$ \\
\hline Missing & $67(3.1)$ & $4.18(3.24-5.31)$ & $108(5.4)$ & $6.74(5.53-8.14)$ & $57(2.9)$ & $3.56(2.70-4.61)$ & $12(4.0)$ & $0.75(0.39-1.31)$ \\
\hline Died & 694 (31.7) & - & 1842 (91.7) & - & $141(7.1)$ & - & $42(14.0)$ & - \\
\hline
\end{tabular}

Note: $\mathrm{Cl}$ = confidence interval.

${ }^{*}$ Classified as assault, unintentional, self-harm or undetermined using International Statistical Classification of Diseases and Related Health Problems, 10th Revision, enhanced Canadian version codes. ${ }^{18}$ Intent was unknown in 4 cases.

†Data missing for 96 people.

$\ddagger$ Assessed with the Rurality Index for Ontario. ${ }^{22}$

Two-thirds (1366/2009 [68.0\%]) of injuries secondary to self-harm occurred in men aged 45 or older living in predominantly rural areas across all income quintiles. The case fatality rate of injuries secondary to self-harm was $91.7 \%$.

\section{Regional rates of injury and death}

Overall rates of firearm-related injuries and deaths were consistently higher in rural areas than in large urban areas. The major driver of this difference was the higher rate of self-harm in rural versus large urban areas (Table 2). Similarly, overall rates of injuries varied across Census divisions and ranged from a high of 12.79 per $100000(95 \% \mathrm{Cl} 8.28-19.88)$ to a low of 1.34 per 100000 (95\% Cl 1.08-1.64) (Figure 2). As expected, the overall rate of injuries and the rate of injuries by intent varied across Census divisions. Self-harm ranged from a high of 7.45 per 100000 (95\%
$\mathrm{Cl} 4.41-11.77)$ to a low of 0.34 per 100000 (95\% Cl 0.26-0.43) (Figure 3, Figure 4). The 10 Census divisions with the highest firearm injury rate secondary to self-harm all had populations of less than 100000 . In contrast, rates of injuries secondary to assault ranged from a high of 3.04 per $100000(95 \% \mathrm{Cl} 2.87-3.22)$ to a low of 0.07 per 100000 (95\% Cl 0.0-0.37) across Census divisions. Of the 10 Census divisions with the highest injury rate secondary to assault, 5 were located in the Greater Toronto Area and Hamilton. There was minimal overlap between the Census divisions with the highest self-harm rate and those with the highest assault rate.

\section{Changes over time}

Rates of firearm-related injury and death varied over the study period. Injury rates peaked in 2005/06 (4.71 per 100000) and 


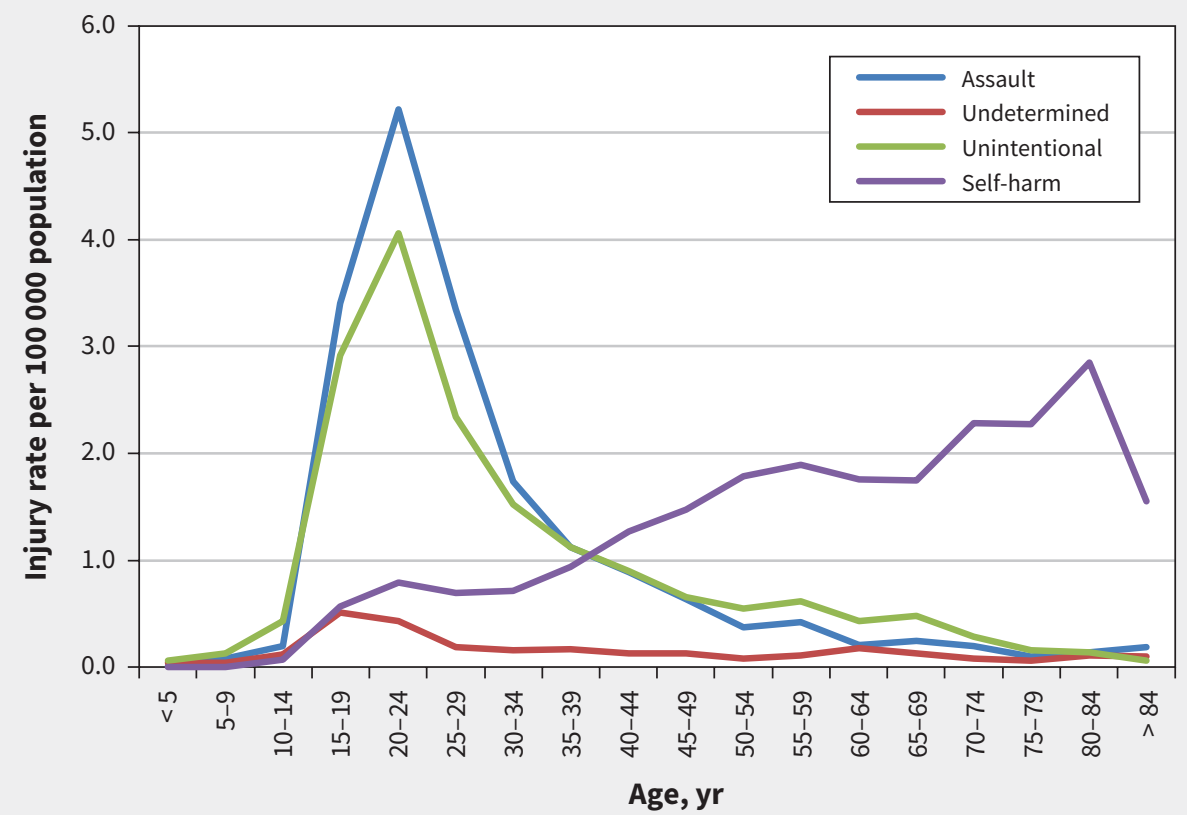

Figure 1: Rate of firearm-related injuries by age group and intent in Ontario, 2002/03 to 2016.

declined every year thereafter until 2013/14, reaching a low of 2.88 per 100000 (Figure 5). Subsequently, rates increased, with injury rates rising to 3.51 per 100000 in 2015/16. The number of injuries in the period Apr. 1-Dec. 31, 2016 exceeded that in the equivalent period in the previous year. Both the 2005/06 and 2015/16 peaks were associated primarily with increases in injuries and deaths secondary to assault. Self-harm rates showed less variability over time, ranging from a low of 0.87 per 100000 to a high of 1.34 per 100000.

\section{Interpretation}

We identified almost 6500 firearm-related injuries in Ontario between Apr. 1, 2002, and Dec. 31, 2016 (annualized injury rate 3.54 per 100000 population); this is equivalent to more than 1 firearm-related injury per day. Injury and death rates varied by intent, age, sex, income quintile and rurality. Injuries secondary to assault accounted for $40 \%$ of nonfatal injuries and $25 \%$ of deaths. Young men within the lowest income quintile were overrepresented in this group. The greatest source of morbidity and mortality due to firearm injuries was self-harm. Older men living in rural areas across all income quintiles were overrepresented in this group. Self-harm accounted for $68 \%$ of all deaths. This is equivalent to a firearm-related injury secondary to self-harm every 3 days; $92 \%$ of these injuries were fatal.

In a study of demographic characteristics of people with firearm-related injury in Canadian trauma centres, Finley and colleagues ${ }^{23}$ found that predominantly young men sustained firearm injuries secondary to assault, and older men were more likely to have injuries secondary to self-harm. Macpherson and Schull ${ }^{24}$ also found variation by gender: in their study, $89 \%$ of firearmrelated injuries presenting to an emergency department in Ontario occurred in men. Our study builds on their findings by including prehospital deaths and people treated outside of trauma centres, and adds insight into the socioeconomic status of victims of firearm injury. Similar patterns regarding intent, age and sex have been observed in the United States. ${ }^{14}$ Racial disparities are also prevalent in the US, where African-American men have rates of firearmrelated death rates as much as 15 times higher than those for White men. ${ }^{25-27}$ Racial disparities were not evaluated in our study.

People who were injured and those who died secondary to assault-related injuries lived predominantly in urban neighbourhoods, whereas injuries secondary to self-harm occurred predominantly in rural Ontario. Similar trends have been observed in the US, with higher rates of suicide by firearm in rural counties than in urban counties. ${ }^{28,29}$ This urban-rural divide highlights the need for tailored interventions to address these 2 contrasting injury patterns. Higher rates of firearm ownership in rural regions may contribute to the higher rates of firearm-related injuries secondary to self-harm in rural Ontario. Households in places with a population less than 10000 reported firearm ownership rates of 34\%, compared to $18 \%$ in places with populations of $10000-100000$ and $1.2 \%$ in cities with populations greater than 1 million. ${ }^{30}$ The presence of a firearm in the home is a recognized risk factor for all types of firearm injuries and has been associated with a fivefold increase in the likelihood of suicide. ${ }^{31-34}$ Reductions in rates of firearm ownership are associated with reduced firearm-related suicides and 


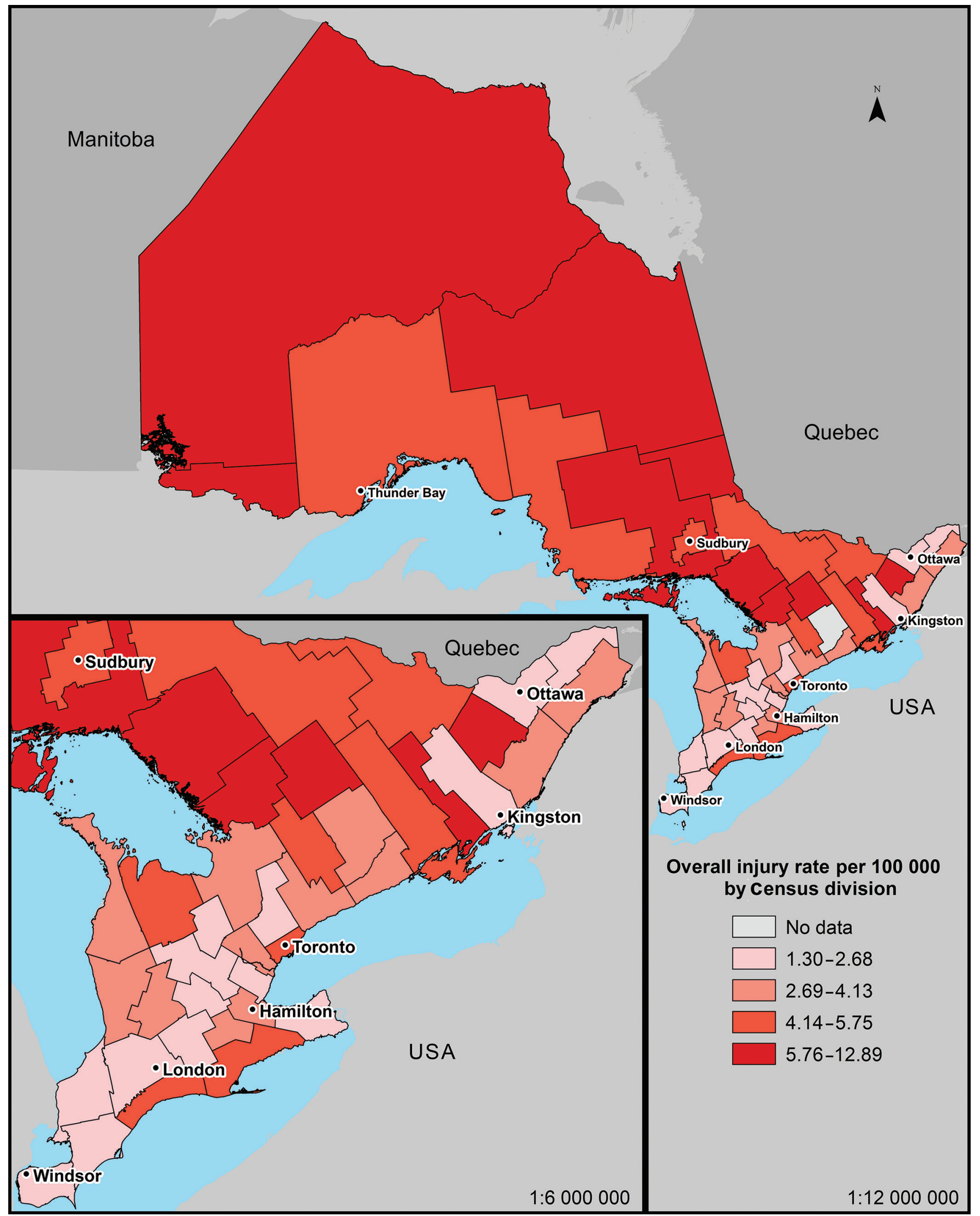

Figure 2: Overall rates per 100000 population of firearm-related injuries by Census division, 2002/03 to 2016 . 


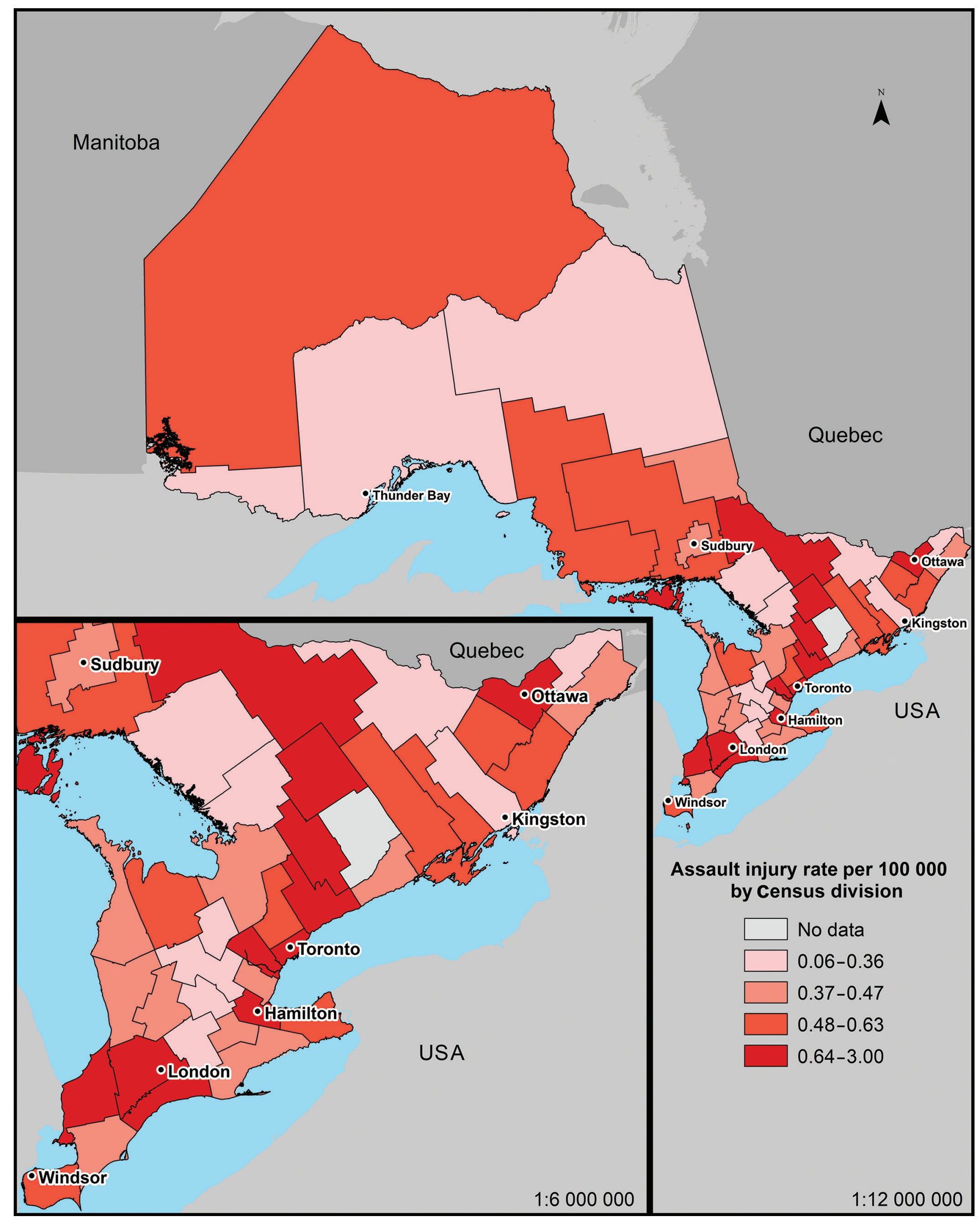

Figure 3: Rates per 100000 population of firearm-related injuries secondary to assault by Census division, 2002/03 to 2016. 


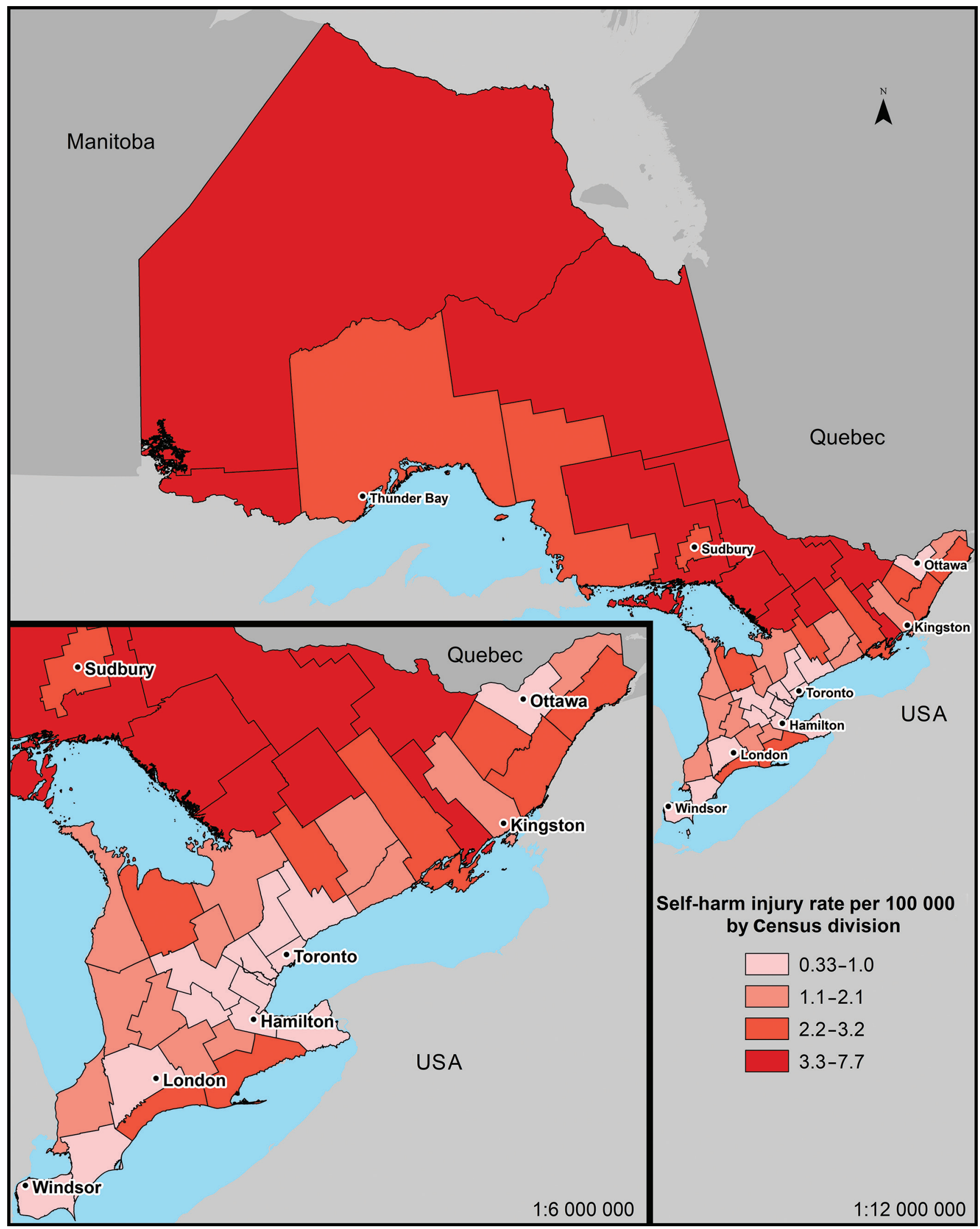

Figure 4: Rates per 100000 population of firearm-related injuries secondary to self-harm by Census division, 2002/03 to 2016. 


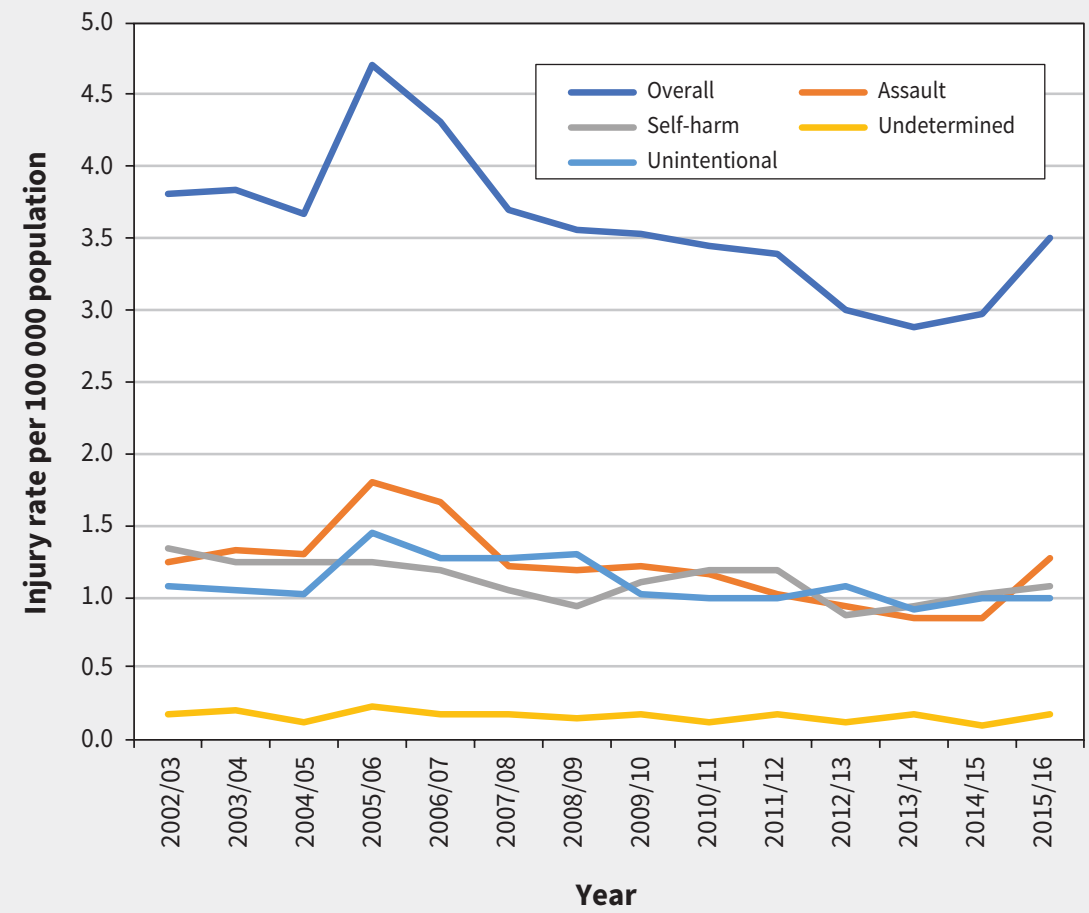

Figure 5: Firearm-related injuries and deaths per 100000 population by intent, 2002/03 to 2015/16.

overall suicide rates. ${ }^{35-39}$ Access to, knowledge of and fluency with lethal means is especially relevant to suicide by firearm. ${ }^{40,41}$ Our findings highlight the need for suicide-prevention strategies in rural Ontario targeted at men aged 45 or older. Restricting access to lethal methods by such means as safe-storage campaigns ${ }^{42,43}$ and reduction in firearm ownership must go hand in hand with depression screening and treatment.

Research and interventions driven by health care workers to prevent firearm-related injuries and death in Canada lag behind those for less common and less lethal conditions. Canadian health care providers and researchers have worked together to minimize morbidity and mortality due to important public health concerns including smoking, ${ }^{44}$ asbestos exposure ${ }^{45}$ and motor vehicle collisions. ${ }^{46}$ With a public health lens, the focus may be shifted to a collaborative approach to preventing firearm-related injuries and death that emphasizes targeted injury-prevention strategies, population-level interventions and system change. ${ }^{47}$ Several other countries have shown that firearm-related injury and death are largely preventable and that policy change can have considerable impact. ${ }^{48-54}$ Although media attention focuses largely on firearm violence in urban centres, our findings highlight that men in rural Ontario are at high risk for death from firearm-related injuries secondary to self-harm. Different injuryprevention strategies may be needed to address specific at-risk groups in different settings.

\section{Limitations}

The data sets available at ICES have inherent limitations that affect our study. Detailed information on types of firearm used is not available, as ICD-10-CA codes are derived from medical charts and not from police records. In addition, there is potential for misclassification of intent and overestimation of unintentional injuries, as medical records do not often contain details on the circumstances of the event. We did not have access to any information regarding the legality of the firearms. The type of firearm and its legality have implications for policy-planning and prevention strategies. Furthermore, people without OHIP coverage at the time of their injury are not captured in the data sets; firearm-related injuries in this population are not accounted for in our analysis.

\section{Conclusion}

Our population-based study sheds light on the sociodemographic characteristics of people who sustain firearm injuries and the magnitude of firearm-related injury as a public health problem in Ontario. Self-harm among older men in rural areas was the major source of morbidity and mortality, followed by assault among young men living in low-income urban neighbourhoods. A public health approach with tailored interventions is likely needed to address this urban-rural divide, and research on effective prevention strategies is required. 


\section{References}

1. Naghavi M, Marczak LB, Kutz M, et al. Global mortality from firearms, 19902016. JAMA 2018;320:792-814.

2. Clermont Y. Firearm-related crime in Canada. Ottawa: Statistics Canada; 2019.

3. Firearm-related violent crime in Canada. Ottawa: Statistics Canada; 2018.

4. Morgan ER, Rowhani-Rahbar A, Azrael D, et al. Public perceptions of firearmand non-firearm-related violent death in the United States: a national study. Ann Intern Med 2018;169:734-7.

5. Genovesi AL, Donaldson AE, Morrison BL, et al. Different perspectives: a comparison of newspaper articles to medical examiner data in the reporting of violent deaths. Accid Anal Prev 2010;42:445-51.

6. Table 13-10-0156-01 deaths, by cause, chapter XX: external causes of morbidity and mortality (V01 to Y89). Ottawa: Statistics Canada. Available: https:// www150.statcan.gc.ca/t1/tbl1/en/tv.action?pid=1310015601 (accessed 2019 Mar. 25).

7. Shenassa ED, Catlin SN, Buka SL. Lethality of firearms relative to other suicide methods: a population-based study. J Epidemiol Community Health 2003;57: 120-4.

8. Burrows S, Auger N, Gamache P, et al. Leading causes of unintentional injury and suicide mortality in Canadian adults across the urban-rural continuum. Public Health Rep 2013;128:443-53.

9. Bridges FS. Gun control law (Bill C-17), suicide, and homicide in Canada. Psychol Rep 2004;94:819-26.

10. Caron J, Julien M, Huang JH. Changes in suicide methods in Quebec between 1987 and 2000: the possible impact of Bill C-17 Requiring Safe Storage of Firearms. Suicide Life Threaten Behav 2008;38:195-208.

11. Langmann C. Canadian firearms legislation and effects on homicide 1974 to 2008. J Interpers Violence 2012;27:2303-21.

12. Leenaars AA, Moksony F, Lester D, et al. The impact of gun control (Bill C-51) on suicide in Canada. Death Stud 2003;27:103-24.

13. Cheung $A H$, Dewa $C S$. Current trends in youth suicide and firearms regulations. Can J Public Health 2005;96:131-5.

14. Gani F, Sakran JV, Canner JK. Emergency department visits for firearm-related injuries in the United States, 2006-14. Health Aff (Millwood) 2017;36:1729-38.

15. Kalesan B, Adhikarla C, Pressley JC, et al. The hidden epidemic of firearm injury: increasing firearm injury rates during 2001-2013. Am J Epidemiol 2017; 185:546-53.

16. Spitzer SA, Vail D, Tennakoon L, et al. Readmission risk and costs of firearm injuries in the United States, 2010-2015. PLoS One 2019;14:e0209896.

17. Fahimi J, Larimer E, Hamud-Ahmed W, et al. Long-term mortality of patients surviving firearm violence. Inj Prev 2016;22:129-34.

18. Holder Y, Peden M, Krug E. Injury surveillance guidelines. Geneva: World Health Organization; 2001.

19. Firearms Act (S.C. 1995, c. 39)

20. College of Physicians and Surgeons of Ontario. Mandatory and permissive reporting. November 2000; updated October 2017. Available: www.cpso.on.ca/ Physicians/Policies-Guidance/Policies/Mandatory-and-Permissive-Reporting (accessed 2020 Sept. 29).

21. Buajitti E, Chiodo S, Rosella LC. Agreement between area- and individual-level income measures in a population-based cohort: implications for population health research. SSM Popul Health 2020;10:100553.

22. Kralj B. Measuring rurality - RIO2008BASIC: methodology and results. Toronto: Ontario Medical Association; 2009.

23. Finley CJ, Hemenway D, Clifton J, et al. The demographics of significant firearm injury in Canadian trauma centres and the associated predictors of inhospital mortality. Can J Surg 2008;51:197-203.

24. Macpherson AK, Schull MJ. Penetrating trauma in Ontario emergency departments: a population-based study. CJEM 2007;9:16-20.

25. Wintemute GJ. The epidemiology of firearm violence in the twenty-first century United States. Annu Rev Public Health 2015;36:5-19.

26. Fleegler E. Mass shootings and the numbing of America. JAMA Intern Med 2019; 179:610-1.

27. Dare AJ, Irving H, Guerrero-Lopez CM, et al. Geospatial, racial, and educational variation in firearm mortality in the USA, Mexico, Brazil, and Colombia, 1990-2015: a comparative analysis of vital statistics data. Lancet Public Health 2019;4:e281-90.
28. Branas CC, Nance ML, Elliott MR, et al. Urban-rural shifts in intentional firearm death: different causes, same results. Am J Public Health 2004;94:1750-5.

29. Nestadt PS, Triplett P, Fowler DR, et al. Urban-rural differences in suicide in the state of Maryland: the role of firearms. Am J Public Health 2017;107: 1548-53.

30. Block R. Firearms in Canada and eight other Western countries: selected findings of the 1996 International Crime (Victim) Survey. Ottawa: Department of Justice Canada; 1998.

31. Anglemyer A, Horvath T, Rutherford G. The accessibility of firearms and risk fo suicide and homicide victimization among household members: a systematic review and meta-analysis. Ann Intern Med 2014;160:101-10.

32. Kellermann AL, Rivara FP, Somes G, et al. Suicide in the home in relation to gun ownership. N Engl J Med 1992;327:467-72.

33. Studdert DM, Zhang Y, Swanson SA, et al. Handgun ownership and suicide in California. N Engl J Med 2020;382:2220-9.

34. Miller M, Barber C, White RA, et al. Firearms and suicide in the United States: Is risk independent of underlying suicidal behavior? Am J Epidemiol 2013;178: 946-55.

35. Rodríguez Andrés A, Hempstead K. Gun control and suicide: the impact of state firearm regulations in the United States, 1995-2004. Health Policy 2011; 101:95-103.

36. Miller M, Azrael D, Hepburn L, et al. The association between changes in household firearm ownership and rates of suicide in the United States, 1981-2002. Inj Prev 2006;12:178-82.

37. Ajdacic-Gross V, Killias M, Hepp U, et al. Changing times: a longitudinal analy sis of international firearm suicide data. Am J Public Health 2006;96:1752-5.

38. Killias M. International correlations between gun ownership and rates of homicide and suicide. CMAJ 1993;148:1721-5.

39. Conner KR, Zhong Y. State firearm laws and rates of suicide in men and women. Am J Prev Med 2003;25:320-4.

40. Houtsma C, Butterworth SE, Anestis MD. Firearm suicide: pathways to risk and methods of prevention. Curr Opin Psychol 2018;22:7-11.

41. Anestis MD, Capron DW. Deadly experience: the association between firing a gun and various aspects of suicide risk. Suicide Life Threat Behav 2018;48: 699-708.

42. Shenassa ED, Rogers ML, Spalding KL, et al. Safer storage of firearms at home and risk of suicide: a study of protective factors in a nationally representative sample. J Epidemiol Community Health 2004;58:841-8.

43. Horn A, Grossman DC, Jones W, et al. Community based program to improve firearm storage practices in rural Alaska. Inj Prev 2003;9:231-4.

44. Levy DT, Ellis JA, Mays D, et al. Smoking-related deaths averted due to three years of policy progress. Bull World Health Organ 2013;91:509-18.

45. Dummer T, Gotay C. Asbestos in Canada: time to change our legacy. CMAJ 2015;187:E315-6.

46. Waller PF. Challenges in motor vehicle safety. Annu Rev Public Health 2002;23: 93-113.

47. Hemenway D. Reducing firearm violence. Crime Justice 2017;46:201-30.

48. Marinho de Souza MF, Macinko J, Alencar AP, et al. Reductions in firearmrelated mortality and hospitalizations in Brazil after gun control. Health Aff (Millwood) 2007;26:575-84.

49. Villaveces $A$, Cummings $P$, Espitia VE, et al. Effect of a ban on carrying firearms on homicide rates in 2 Colombian cities. JAMA 2000;283:1205-9.

50. Kapusta ND, Etzersdorfer E, Krall C, et al. Firearm legislation reform in the European Union: impact on firearm availability, firearm suicide and homicide rates in Austria. Br J Psychiatry 2007;191:253-7.

51. Beautrais AL, Fergusson DM, Horwood LJ. Firearms legislation and reductions in firearm-related suicide deaths in New Zealand. Aust N Z J Psychiatry 2006;40: 253-9.

52. Ozanne-Smith J, Ashby K, Newstead S, et al. Firearm related deaths: the impact of regulatory reform. Inj Prev 2004;10:280-6.

53. Dudley MJ, Rosen A, Alpers PA, et al. The Port Arthur massacre and the National Firearms Agreement: 20 years on, what are the lessons? Med J Aust 2016;204:381-3.

54. Chapman S, Alpers P, Agho K, et al. Australia's 1996 gun law reforms: faster falls in firearm deaths, firearm suicides, and a decade without mass shootings. Inj Prev 2015;21:355-62. 
Competing interests: David Gomez and Najma Ahmed are members of a number of national and international medical associations that advocate for the reduction of firearm injuries. These include the American College of Surgeons, the Trauma Association of Canada, and the Panamerican Trauma Society. In addition, David Gomez and Najma Ahmed are members of the Canadian Doctors for Protection from Guns, which is an advocacy group. The current work does not represent any of these societies or advocacy groups. No other competing interests were declared.

This article has been peer reviewed.

Affiliations: Division of General Surgery (Gomez, Greene, Ahmed), Department of Surgery, University of Toronto; Division of General Surgery (Gomez, Ahmed), St. Michael's Hospital, Unity Health Toronto; Li Ka Shing Knowledge Institute (Gomez, Ahmed, Baxter), St. Michael's Hospital, Unity Health Toronto; ICES (Gomez, Saunders, Santiago, Baxter); Division of Pediatric Medicine (Saunders), The Hospital for Sick Children; Department of Pediatrics (Saunders), University of Toronto; Institute of Health Policy, Management and Evaluation (Saunders, Baxter), Dalla Lana School of Public Health, University of Toronto, Toronto, Ont.; Melbourne School of Population and Global Health (Baxter), University of Melbourne, Melbourne, Australia

Contributors: David Gomez and Nancy Baxter conceived and designed the study. David Gomez, Robin Santiago, Natasha Saunders and Nancy Baxter analyzed the data. David Gomez, Natasha Saunders and Nancy Baxter interpreted the data. All of the authors contribured to drafting the manuscript, and David Gomez, Brittany Greene, Natasha Saunders and Nancy Baxter revised it critically for important intellectual content. All of the authors approved the final version to be published and agreed to be accountable for all aspects of the work.
Funding: This study was supported by St. Michael's Hospital Medical Service Association 2018-2019 Alternative Funding Plan Innovation Fund.

Data sharing: The data set from this study is held securely in coded form at ICES. Although data-sharing agreements prohibit ICES from making the data set publicly available, access may be granted to those who meet prespecified criteria for confidential access, available at https://www.ices.on.ca/DAS. The full data set creation plan and underlying analytic code are available from the authors on request, with the understanding that the programs may rely on coding templates or macros that are unique to ICES.

Acknowledgement: Kristian Larsen generated the figures depicting geographic variation in firearm-related injury and death.

Disclaimer: This study was supported by ICES, which is funded by an annual grant from the Ontario Ministry of Health and Long-Term Care (MOHLTC). The opinions, results and conclusions reported in this paper are those of the authors and are independent from the funding sources. No endorsement by ICES or the Ontario MOHLTC is intended or should be inferred. The original source of Office of the Registrar General Deaths is Service Ontario. The views expressed herein are those of the authors and do not necessarily reflect those of the Office of the Registrar General or the Ministry of Government Services. Parts of this material are based on data or information compiled and provided by the Canadian Institute for Health Information ( $\mathrm{ClHI}$ ). However, the analyses, conclusions, opinions and statements expressed in the material are those of the authors and not necessarily those of $\mathrm{ClHI}$.

Accepted: June 16, 2020

Correspondence to: David Gomez, david.gomez@unityhealth.to 